\title{
Complex chronic patients as an emergent group with high risk of intracerebral haemorrhage: an observational cohort study
}

Blanca Lorman-Carbó ${ }^{1} \mathbb{D}$, Josep Lluís Clua-Espuny ${ }^{2^{*}}$ (D) Eulàlia Muria-Subirats ${ }^{3}$, Juan Ballesta-Ors ${ }^{4}$, Maria Antònia González-Henares ${ }^{5}$, José Fernández-Sáez ${ }^{6}$, Francisco M. Martín-Luján7 , on behalf Ebrictus Research Group

\begin{abstract}
Background: Demographic aging is a generalised event and the proportion of older adults is increasing rapidly worldwide with chronic pathologies, disability, and complexity of health needs. The intracerebral haemorrhage (ICH) has devastating consequences in high risk people. This study aims to quantify the incidence of ICH in complex chronic patients (CCP).

Methods: This is a multicentre, retrospective and community-based cohort study of 3594 CCPs followed up from 01/01/2013 to 31/12/2017 in primary care without a history of previous ICH episode. The cases were identified from clinical records encoded with ICD-10 (10th version of the International Classification of Diseases) in the e-SAP database of the Catalan Health Institute. The main variable was the ICH episode during the study period. Demographic, clinical, functional, cognitive and pharmacological variables were included. Descriptive and logistic regression analyses were carried out to identify the variables associated with suffering an $\mathrm{ICH}$. The independent risk factors were obtained from logistic regression models, ruling out the variables included in the HAS-BLED score, to avoid duplication effects. Results are presented as odds ratio (OR) and 95\% confidence interval (Cl). The analysis with the resulting model was also stratified by sex.

Results: 161 (4.4\%) participants suffered an ICH episode. Mean age $87 \pm 9$ years; 55.9\% women. The ICH incidence density was $151 / 10000$ person-years [95\%Cl 127-174], without differences by sex. Related to subjects without ICH, presented a higher prevalence of arterial hypertension ( $83.2 \%$ vs. $74.9 \% ; p=0.02)$, hypercholesterolemia (55.3\% vs. $47.4 \%, p=0.05)$, cardiovascular disease (36.6\% vs. $28.9 \% ; p=0.03)$, and use of antiplatelet drugs (64.0\% vs. $52.9 \%$; $p=0.006) .93 .2 \%$ had a HAS-BLED score $\geq 3$. The independent risk factors for $\mathrm{ICH}$ were identified: HAS-BLED $\geq 3$ [OR 3.54; 95\%Cl 1.88-6.68], hypercholesterolemia [OR 1.62; 95\%Cl 1.11-2.35], and cardiovascular disease [OR 1.48 IC95\% 1.05-2.09]. The HAS_BLED $\geq 3$ score showed a high sensitivity [0.93 Cl95\% 0.89-0.97] and negative predictive value [0.98 (C195\% 0.83-1.12)].

(Continued on next page)
\end{abstract}

\footnotetext{
* Correspondence: jlclua@telefonica.net

${ }^{2}$ Department of Primary Care, Catalonian Health Institute, University Rovira i

Virgili, CAP El Temple, Plaça Carrilet s/n. 43500, Tortosa, Catalunya, Spain

Full list of author information is available at the end of the article
}

(c) The Author(s). 2021 Open Access This article is licensed under a Creative Commons Attribution 4.0 International License, which permits use, sharing, adaptation, distribution and reproduction in any medium or format, as long as you give appropriate credit to the original author(s) and the source, provide a link to the Creative Commons licence, and indicate if changes were made. The images or other third party material in this article are included in the article's Creative Commons licence, unless indicated otherwise in a credit line to the material. If material is not included in the article's Creative Commons licence and your intended use is not permitted by statutory regulation or exceeds the permitted use, you will need to obtain permission directly from the copyright holder. To view a copy of this licence, visit http://creativecommons.org/licenses/by/4.0/ The Creative Commons Public Domain Dedication waiver (http://creativecommons.org/publicdomain/zero/1.0/) applies to the data made available in this article, unless otherwise stated in a credit line to the data. 
(Continued from previous page)

Conclusions: In the CCP subgroup the incidence density of ICH was 5-60 times higher than that observed in elder and general population. The use of bleeding risk score as the HAS-BLED scale could improve the preventive approach of those with higher risk of $\mathrm{ICH}$.

Trial registration: This study was retrospectively registered in ClinicalTrials.gov (NCT03247049) on August 11/2017.

Keywords: Cardiovascular, Intracerebral haemorrhage, Complex chronic patient, HAS-BLED score

\section{Background}

Demographic ageing, which is an almost universal generalized event, has important consequences and repercussions in practically all domains. In healthcare, we are faced with an epidemic of chronic pathologies, disability, and complex health needs, particularly in the older adult population [1]. This phenomenon has led to the emergence of concepts such as 'comorbidity', 'multimorbidity' and, more recently, 'clinical complexity' and 'complex chronic patient' (CCP) [2]. The latter is an emerging concept that aims to group intertwined conditions such as multimorbidity, frailty, ageing, and/or sarcopenia. The common element would be the state of clinical vulnerability, which integrates different risk criteria associated with demographic and social evolution. Approximately 4 to 5\% of the Catalan population is categorised as CCPs [3] and consumes $65 \%$ of health resources. These patients present more frequent and complex interactions with healthcare services, which lead to greater susceptibility to failures in care delivery and coordination. Furthermore, these patients are usually prescribed a broad range of drugs, which leads to poor medication adherence and adverse drug events and interactions. The care of patients with complex chronic conditions is a very challenging area due to the greater and new needs of these patients and offers an opportunity to explore clinical risk assessment modalities and prevention policies, including the identification of vulnerable groups, the analysis of population morbidity and the selection of controls for epidemiological studies [see Additional file 1].

The World Health Organization estimates that the population aged over 60 years will almost double by 2050 [4]. This population group is expected to exhibit an increased incidence of intracerebral haemorrhage (ICH), which is already high in the general population [5]. The incidence of $\mathrm{ICH}$ has significantly increased in older adults, which usually present multiple comorbidities, although some peculiarities have been detected depending on the type of population studied. These individuals exhibit a poor prognosis due to the lethality and disability of $\mathrm{ICH}[6,7]$. The European Stroke Organization and the Stroke Alliance for Europe have proposed decreasing the $\mathrm{ICH}$ mortality and improving disability outcomes [8] but have not defined specific preventive actions for the identification and control of predisposing factors or interventions according to risk stratification in specific populations such as CCPs.

Studying ICH in this population group is important for obtaining a better understanding of the disease, identifying methods for its prevention, and aiding treatment decisions because the available evidence of this condition is limited despite its clinical relevance and its associated adverse outcomes. Therefore, the main goals of the present study were to quantify the incidence of $\mathrm{ICH}$ in primary healthcare centres and to identify the associated risk factors in a cohort of CCPs.

\section{Material and methods \\ Study design}

This is a multicentre, retrospective and communitybased cohort study conducted with CCPs who were followed up for 5 years (from 01/01/2013 to 31/12/2017) in primary care centres in the Terres de l'Ebre health area, Catalonia, Spain [see Additional file 2]. This geographical area includes a hospital with secondary care services, 11 primary care teams operating collaboratively with the hospital, a nursing home, and social and mental healthcare services, which conform to a model oriented to coping with the enhanced needs and demands generated by frequent acute exacerbations and intensive use of healthcare services.

\section{Patients}

All patients with an active medical history in any of the participating centres were included in the study. The clinical records should include the condition of CCP at the beginning of the study, and the patients should be living in the study area, including long-term nursing/ residential care facilities in the study area. CCP was defined by the presence of at least four of the following criteria [3]: (1) age $\geq 65$ years; (2) $\geq 4$ active comorbidities; (3) geriatric conditions with functional disability (Barthel Index score $<60$, long-term institutionalisation in a nursing/residential care home, or caregivers at home) or recurrent falls; (4) psychosocial disorders (cognitive or psychological disorder with functional disability); (5) active treatment with $\geq 4$ drugs during the previous 6 months; (6) living alone or with a caregiver ( $\geq 75$ years); 
and (7) use of unscheduled hospital care (two admissions or three emergency room visits due to the exacerbation of chronic diseases) during the previous year.

Patients who had suffered a previous $\mathrm{ICH}$ episode or those with a diagnosis of progressive and irreversible advanced chronic disease [3] with a low probability of responding to specific treatments and with a limited life prognosis were excluded. Patients for whom clinical records could not be accessed and/or itinerant or displaced people were also excluded.

\section{Variables}

The main variable was the diagnosis of $\mathrm{ICH}$ episodes (coded as I60-70) during the study period. The follow-up time was established from their registration as CCPs in the clinical records until the end of the study, an occurrence of an $\mathrm{ICH}$ event, or death from any cause.

We collected the following demographic, clinical, functional, cognitive, and pharmacological variables: age and sex; arterial hypertension (HT) and mean blood pressure (BP; in $\mathrm{mmHg}$ and as an average of the measurements obtained in the previous 6 months); cardiovascular diseases, including diagnoses of ischaemic heart diseases, stroke or transient ischaemic accident and/or peripheral arterial disease; and previous falls, presence of cognitive impairment (active diagnosis and/or Pfeiffer's test $>2$ [9]) and/or active prescription of specific medication (antidepressants, sedatives and/or other drugs with effects on the neurological system). The Barthel Index (>60) [10] and/or the modified Rankin scale (>4) [11] were used for the assessment of functionality in the basic activities of daily life. The patients were considered institutionalised if they lived in a long-term nursing/residential care home.

The $\mathrm{CHA}_{2} \mathrm{DS}_{2}$-VASC score was available only for AF patients. The risk of bleeding was calculated using the HAS-BLED score [12], regardless of the diagnosis of atrial fibrillation or the prescription of anticoagulant therapy. This measuring scale exhibits good predictive value for intracranial bleeding in anticoagulated patients with atrial fibrillation, although it has also been used for patients without atrial fibrillation and with acute coronary disease [13]. The scale, which has been well validated worldwide and is easy to apply, contains the following variables: age $>65$ years; uncontrolled hypertension defined as a mean $\mathrm{SBP} \geq 160 \mathrm{mmHg}$ among those with hypertension; abnormal kidney and/or liver function; previous ischaemic stroke; history of bleeding or predisposition; labile INR, defined as time in the therapeutic range during the previous 6 months $<60 \%$ (only for patients receiving vitamin $\mathrm{K}$ antagonists); and concomitant use of medications (antiplatelet drugs and/or nonsteroidal anti-inflammatory drug [NSAIDs]) and/or alcohol consumption. A HAS-BLED score $\geq 3$ indicates an increased risk of bleeding [14]. The HAS-BLED score is considered a useful tool due to the relatively high prevalence of the variables in the CCP population. In addition, this score note the need for regular clinical review and close follow-up and makes clinicians consider potentially reversible bleeding risk factors.

\section{Data source}

The Chronicity Prevention and Care Programme set up by the Health Plan for Catalonia (2011) implemented a new integrated care model for an increasing number of populations with concurrent health and social needs, particularly CCPs with multimorbidity, complexity or advanced chronic disease as well as social needs or dependence [3]. This implementation led to a new scenario where it was possible to work collaboratively with new tools such as integrated health information systems. The Catalan Health Plan extensively implemented a case finding system that classifies high-risk chronic patients into two different categories based on defined criteria and primary care physician judgement: i) complex chronic patients (CCPs, approximately $5 \%$ of the population) and ii) patients with advanced chronic disease and a life expectancy of less than 12 months (approximately $1 \%$ of the population). The medical records, including the CCP condition, were incorporated into the computerized medical records of the Catalan Health Institute in January 2013. This database is managed by primary care professionals, who administer and update it in a specific format called the "shared individual intervention plan" (PIIC, Catalan acronym for Pla d'Intervenció Individualitzat Compartit) [8]. Currently, $82 \%$ of individuals registered as CCPs have an updated report.

The cases were identified from clinical records encoded with ICD-10 (10th version of the International Classification of Diseases) in the e-SAP database of the Catalan Health Institute. The Department of Information and New Technologies performed an automated extraction of the CMBD of hospital discharges and SIRE (Integrated Electronic Prescription System, Catalan acronym for Sistema Integrat de Recepta Electrònica). All the data were included in an ad hoc repository, which was delivered to the main researcher in a completely anonymous format, supervised and assessed according to the General Data Protection Regulation of Spain/Europe of 1st February 2017. For this type of study, formal consent is not required, and the requirement for informed patient consent was waived prior to the inclusion of their medical data in this study. The datasets generated during and/or analysed during the current study are available in the public repository (https://doi.org/10. 1007/s12325-019-01206-y). 


\section{Statistical analysis}

A descriptive analysis was performed using frequencies and percentages for the qualitative variables and means with standard deviations for the continuous variables. This analysis was stratified by group according to whether the patients had suffered from ICH. We assessed differences in proportions and used the nonparametric Mann-Whitney $U$-test to detect significant differences between the two groups. The total incidence density of ICH was calculated by sex and adjusted for age groups. We calculated the incidence rate ratio for $\mathrm{ICH}$ risk factors among the exposed portion of the population compared with the unexposed portion. The independent risk factors were obtained from logistic regression models, and the variables included in the HASBLED score were ruled out to avoid duplication effects. All variables with a significant $p$-value $\leq 0.05$ for basal differences between the group with $\mathrm{ICH}$ and that without ICH were introduced in the multivariate model, which considered those variables associated with a higher risk of ICH based on the available evidence [15] and its clinical significance regardless of its removal by the procedure. The results are presented as odds ratios and 95\% confidence intervals (CIs). The analysis with the resulting model was also stratified by sex. All the analyses were performed using SPSS 24.0 statistical software.

\section{Results}

The present study assessed 3594 cases registered as CCP, and $55.2 \%$ of these subjects were women. The mean age of the participants was $84 \pm 11$ years. A total of 271 patients $(7.5 \%)$ were institutionalised at the beginning of the study. During the follow-up period, 60 patients (1.7\%) moved outside the area of study, and 1692 (47.1\%) died. The baseline characteristics of this population are illustrated in Table 1 according to whether they experienced an $\mathrm{ICH}$ episode during the follow-up period.

In total, 161 (4.4\%) CCPs suffered an ICH episode, and $55.9 \%$ were women. The mean age of these individuals was $86.5( \pm 8.7)$ years, and women were significantly older $(p<0.001)$. The comparison of these patients with those without $\mathrm{ICH}$ indicated relevant differences with respect to the following factors: history of HT $(83.2 \%$ vs. $74.9 \% ; p=0.017)$; hypercholesterolemia $(55.3 \%$ vs. $47.4 \% ; p=0.051)$; prevalence of cardiovascular disease of any type $(36.6 \%$ vs. $28.9 \%$; $p=0.034)$; and increasing use of antiplatelet drugs (64.0\% vs. $52.9 \% ; p=0.006)$. The most prescribed drugs were proton pump inhibitors $(84.5 \%$ vs. $87.6 \%$; $p=0.238)$ and NSAIDs $(69.6 \%$ vs. $76.1 \% ; p=0.060)$. An HAS-BLED score $\geq 3$ was found in $93.2 \%$ of the group with $\mathrm{ICH}$ vs. $79.81 \%$ of the group without
ICH $(p<0.001)$. The average HAS-BLED score of the ICH group was $3.5 \pm 0.9$, whereas that of the group without $\mathrm{ICH}$ was $3.3 \pm 0.0 \quad(p=0.029)$. The overall mortality of the total population was high (47.1\%), but a significantly higher mortality was found in the ICH group (58.4\% vs. $46.5 \%$; $p=0.003$ ).

Differences were found between the sexes (Table 2). The analysis of the characteristics of patients with $\mathrm{ICH}$ revealed a higher prevalence of cardiovascular diseases in men $(49.3 \%$ vs. $26.7 \%$; $p=$ $0.003)$, particularly ischaemic heart disease $(31.0 \%$ vs. $12.2 \% ; p=0.003)$, chronic kidney disease $(33.8 \%$ vs. $13.3 \% ; p=0.002)$, alcohol consumption $(19.7 \%$ vs. $5.6 \% ; p=0.006)$, bleeding predisposition $(14.1 \%$ vs. $3.3 \% ; p=0.013)$ and use of antiplatelet drugs $(76.1 \%$ vs. $54.4 \% ; p=0.005)$. Men also showed a higher HAS-BLED score (3.7 vs. $3.3 ; p=0.014$ ). In contrast, women exhibited higher frequencies of hypercholesterolemia $(64.4 \%$ vs. $43.7 \% ; p=0.008)$ and falls $(17.8 \%$ vs. $7 \%, p=0.045)$ and an increased use of selective serotonin reuptake inhibitors $(46.7 \%$ vs. 23.9\%; $p=0.003$ ).

The ICH incidence stratified by age group is shown in Table 3. The overall incidence density of $\mathrm{ICH}$ was $151 / 10000$ person-years [95\% CI 127-174], and a higher density was found in men than in women, although this difference did not reach significance (153 [95\% CI 121-184] vs. 148 [95\% CI 114-182], respectively). The incidence rate ratios (IRRs) for $\mathrm{ICH}$ risk factors are shown in Table 4. HT, cardiovascular disease, HAS-BLED score $\geq 3$ and treatment with antiplatelet drugs were associated with a higher rate of $\mathrm{ICH}$, but only the HAS-BLED score, hypercholesterolemia and cardiovascular disease were identified as independent risk factors for ICH episodes. The independent $\mathrm{ICH}$ risk factors for the CCP population and their stratification by sex are shown in Table 5 . The criterion HAS-BLED $\geq 3$ (OR 3.54; 95\% CI 1.886.68; $p<0.001)$ was the most important risk factor in both women (OR 4.22; 95\% CI 1.66-10.71; $p=0.002$ ) and men (OR 2.94; 95\% CI 1.23-7.05; $p=0.015$ ). Additionally, hypercholesterolemia (OR 1.62: 95\% CI $1.11-2.35 ; p=0.012$ ) and cardiovascular disease (OR 1.48 ; $95 \%$ CI $1.05-2.09 ; p=0.026)$ were significant in women (OR 2.09; 95\% CI 1.24-3.51; $p=0.006$ ) and in men (OR 2.15; 95\% CI 1.28-3.61; $p=0.004$ ), respectively. In contrast, heart failure (OR 0.61: 95\% CI $0.41-0.92 ; p=0.018$ ) and treatment with statins (OR $0.62 ; 95 \%$ CI $0.42-0.91 ; p=0.015)$ were associated with lower risk in the entire CPP population but not in the different sexes.

A HAS-BLED score $\geq 3$ showed high sensitivity [0.93; 95\% CI $0.97-0.89$ ], a negative predictive value [0.98; $95 \%$ CI 0.83-1.12)], a low attributable risk [0.036; 95\% CI 
Table 1 Baseline characteristics of CCPa population according to whether or not they had ICH ${ }^{b}$ during follow-up (01/01/2013-31/ 12/2017)

\begin{tabular}{|c|c|c|c|c|}
\hline & $\begin{array}{l}\text { Total } \\
(N=3594)\end{array}$ & $\begin{array}{l}\text { Without } \mathrm{ICH}^{\mathrm{b}} \\
(N=3433)\end{array}$ & $\begin{array}{l}\text { With ICH } \\
(N=161)\end{array}$ & $\mathrm{p}^{*}$ \\
\hline Age & $84.4[11.5]$ & $84.3[11.6]$ & $86.5[8.7]$ & 0.063 \\
\hline$<80$ years $(n 840,23.4 \%)$ & $70.5[9.5]$ & $68.1[11.4]$ & $72.2[8.8]$ & 0.004 \\
\hline$\geq 80$ years $(n) 2754,76.6 \%)$ & $89.4[5.5]$ & $89.3[5.4]$ & $89.5[5.5]$ & 0.638 \\
\hline Sex (women) & $1985(55.2)$ & $1895(55.2)$ & $90(55.9)$ & 0.925 \\
\hline \multicolumn{5}{|l|}{ Cardiovascular risk factors } \\
\hline Arterial hypertension & $2707(75.3)$ & $2573(74.9)$ & $134(83.2)$ & 0.017 \\
\hline Diabetes & $1510(42.0)$ & $1452(42.3)$ & $58(36.0)$ & 0.115 \\
\hline Hypercholesterolemia & $1717(47.8)$ & $1628(47.4)$ & $89(55.3)$ & 0.051 \\
\hline \multicolumn{5}{|l|}{ Comorbidities } \\
\hline Cardiovascular disease & $1050(29.2)$ & $991(28.9)$ & $59(36.6)$ & 0.034 \\
\hline Ischemic cardiopathy & $634(17.6)$ & $601(17.5)$ & $33(20.5)$ & 0.331 \\
\hline Ischemic stroke/Transient ischemic accident & $275(7.7)$ & $259(7.5)$ & $16(9.9)$ & 0.264 \\
\hline Peripheral artery disease & $306(8.5)$ & $289(8.4)$ & $17(10.6)$ & 0.342 \\
\hline Atrial fibrillation & $998(27.8)$ & $947(27.6)$ & $51(31.7)$ & 0.257 \\
\hline Heart failure & $947(26.3)$ & $913(26.6)$ & $34(21.1)$ & 0.123 \\
\hline Thromboembolism & $294(8.2)$ & $281(8.2)$ & $13(8.1)$ & 0.960 \\
\hline Chronic kidney disease & $893(24.8)$ & $857(25)$ & $36(22.4)$ & 0.455 \\
\hline Chronic liver disease & $58(1.6)$ & $57(1.7)$ & $1(0.6)$ & 0.306 \\
\hline \multicolumn{5}{|l|}{ Other conditioning factors } \\
\hline Institutionalized & $271(7.5)$ & $262(7.6)$ & $9(5.6)$ & 0.338 \\
\hline Record of previous falls & $508(14.1)$ & $487(14.2)$ & $21(13.0)$ & 0.684 \\
\hline Cognitive impairment or dementia & $758(21.1)$ & $720(21.0)$ & $38(23.6)$ & 0.424 \\
\hline Alcohol consumption & $506(14.1)$ & $487(14.2)$ & $19(11.8)$ & 0.395 \\
\hline Falls (background) & $508(14.3)$ & $487(14.1)$ & $21(13.0)$ & 0.395 \\
\hline Bleeding predisposition & $285(7.9)$ & $272(7.9)$ & $13(8.1)$ & 0.945 \\
\hline \multicolumn{5}{|l|}{ Clinical data } \\
\hline Systolic blood pressure (mmHg) & $129.8[16.2]$ & $129.6[16.5]$ & $132.8[13.4]$ & 0.032 \\
\hline Glycosylated haemoglobin A1c (\%) & $6.6[2.9]$ & $6.6[3.0]$ & $6.3[1.4]$ & 0.247 \\
\hline Glomerular filtration rate $\left(\mathrm{mL} / \mathrm{min} / 1.73 \mathrm{~m}^{2}\right)$ & $56.8[23.6]$ & $56.4[23.7]$ & $66.5[20.9]$ & 0.093 \\
\hline $\mathrm{CHA}_{2} \mathrm{DS}_{2}$-VASC score** & $4.6[1.5]$ & $4.6[1.5]$ & $4.3[1.5]$ & 0.669 \\
\hline HAS-BLED score & $3.5[1.1]$ & $3.3[0.0]$ & $3.5[0.9]$ & 0.029 \\
\hline Barthel index & $70.2[28.7]$ & $70.1[28.9]$ & $72.4[23.7]$ & 0.988 \\
\hline \multicolumn{5}{|l|}{ Medication } \\
\hline Oral anticoagulant $\left(V_{K A}^{c} \circ N^{\prime} O A C^{d}\right)$ & $1050(29.2)$ & $996(29.0)$ & $54(33.5)$ & 0.217 \\
\hline$N O A C^{d}$ & $106(2.9)$ & $103(3.0)$ & $3(1.9)$ & 0.405 \\
\hline NSAID $^{e}$ & $2723(75.8)$ & $2611(76.1)$ & $112(69.6)$ & 0.060 \\
\hline Antiplatelet drug & $1920(53.4)$ & $1817(52.9)$ & $103(64.0)$ & 0.006 \\
\hline Statin & $2006(55.8)$ & $1921(56.0)$ & $85(52.8)$ & 0.430 \\
\hline $\mathrm{SSRI}^{\mathrm{f}}$ & $1252(34.8)$ & $1193(34.8)$ & 59 (36.6) & 0.622 \\
\hline $\mathrm{PPI}^{9}$ & $3144(87.5)$ & 3008 (87.6) & $136(84.5)$ & 0.238 \\
\hline
\end{tabular}

Data are presented as number of patients (\%) or mean [standard deviation] depending on the type of variable, whether qualitative or continuous, respectively. $\left.{ }^{*}\right)$ The $p$-value corresponds to the contrast of differences in proportions for qualitative variables and the non-parametric test of the MannWhitney U. $\left.{ }^{* *}\right) \mathrm{CHA}_{2} \mathrm{DS}_{2}$-VASC score only in patients with atrial fibrillation

${ }^{a} C C P$ complex chronic patient, ${ }^{b} / C H$ intracerebral haemorrhage, ${ }^{c} V K A$ vitamin $\mathrm{K}$ antagonists, ${ }^{\mathrm{d}} N O A C$ new oral anticoagulant, ${ }^{\mathrm{e}}$ NSAID non-steroidal antiinflammatory drug, ${ }^{\mathrm{f}} \mathrm{S} S R I$ selective serotonin reuptake inhibitors, ${ }^{9} P P I$ Proton pump inhibitor 
Table 2 Comparison of the characteristics of $\mathrm{CCP}^{\mathrm{a}}$ population with $\mathrm{ICH}^{\mathrm{b}}$ according to sex

\begin{tabular}{|c|c|c|c|}
\hline & $\begin{array}{l}\text { Men } \\
(N=71)\end{array}$ & $\begin{array}{l}\text { Women } \\
(N=90)\end{array}$ & $\mathrm{p}^{*}$ \\
\hline Age (years) & $83.6[9.1]$ & $88.9[7.7]$ & $<0.001$ \\
\hline$<80$ years & $72.1[6.9]$ & $72.6[7.0]$ & 0.861 \\
\hline$\geq 80$ years & $87.8[5.5]$ & $90.7[5.3]$ & 0.003 \\
\hline \multicolumn{4}{|l|}{ Cardiovascular risk factors } \\
\hline Arterial hypertension & $60(84.5)$ & $74(82.2)$ & 0.700 \\
\hline Diabetes & $30(42.3)$ & $28(31.1)$ & 0.144 \\
\hline Hypercholesterolemia & $31(43.7)$ & $58(64.4)$ & 0.008 \\
\hline \multicolumn{4}{|l|}{ Comorbidities } \\
\hline Cardiovascular disease & $35(49.3)$ & $24(26.7)$ & 0.003 \\
\hline Ischemic cardiopathy & $22(31.0)$ & $11(12.2)$ & 0.003 \\
\hline Ischemic stroke/Transient ischemic accident & $8(11.3)$ & $8(8.9)$ & 0.616 \\
\hline Peripheral artery disease & $8(11.3)$ & $9(10.0)$ & 0.795 \\
\hline Atrial fibrillation & $17(23.9)$ & $34(37.8)$ & 0.061 \\
\hline Heart failure & $13(18.3)$ & $21(23.3)$ & 0.438 \\
\hline Thromboembolism & $4(5.6)$ & $9(10.0)$ & 0.313 \\
\hline Chronic kidney disease & $24(33.8)$ & $12(13.3)$ & 0.002 \\
\hline Chronic liver disease & $1(1.4)$ & $0(0.0)$ & 0.259 \\
\hline \multicolumn{4}{|l|}{ Other conditioning factors } \\
\hline Institutionalized & $2(2.8)$ & $7(7.8)$ & 0.174 \\
\hline Record of previous falls & $5(7.0)$ & $16(17.8)$ & 0.045 \\
\hline Cognitive impairment or dementia & $13(18.3)$ & $25(27.8)$ & 0.160 \\
\hline Alcohol consumption & $14(19.7)$ & $5(5.6)$ & 0.006 \\
\hline Bleeding predisposition & $10(14.1)$ & $3(3.3)$ & 0.013 \\
\hline \multicolumn{4}{|l|}{ Clinical data } \\
\hline Systolic blood pressure (mmHg) & $134.7[12.2]$ & $131.3[14.3]$ & 0.096 \\
\hline Glycosylated haemoglobin A1c (\%) & $6.6[1.5]$ & $6.1[1.3]$ & 0.039 \\
\hline Glomerular filtration rate $\left(\mathrm{mL} / \mathrm{min} / 1.73 \mathrm{~m}^{2}\right)$ & $66.9[25.3]$ & $65.9[16.7]$ & 1.000 \\
\hline $\mathrm{CHA}_{2} \mathrm{DS}_{2}$-VASC score & $3[0.00]$ & $5.5[0.7]$ & 0.102 \\
\hline HAS-BLED score & $3.7[1.0]$ & $3.3[0.7]$ & 0.014 \\
\hline Barthel index & $70.3[23.7]$ & $75.6[24.7]$ & 0.145 \\
\hline \multicolumn{4}{|l|}{ Medication } \\
\hline Oral anticoagulant $\left(V_{K A}{ }^{c} \circ N^{\prime} O A C^{d}\right)$ & $22(31.0)$ & $32(35.6)$ & 0.542 \\
\hline NOAC & $2.0(2.8)$ & $1.0(1.1)$ & 0.427 \\
\hline NSAID & $49(69.0)$ & $63(70.0)$ & 0.893 \\
\hline Antiplatelet drugs & $54(76.1)$ & $49(54.4)$ & 0.005 \\
\hline Statin & $37(52.1)$ & $48(53.3)$ & 0.878 \\
\hline$\left.\operatorname{SSRI}\right|^{\mathrm{f}}$ & $17(23.9)$ & $42(46.7)$ & 0.003 \\
\hline $\mathrm{PPI}^{\mathrm{g}}$ & $62(87.3)$ & $74(82.2)$ & 0.375 \\
\hline
\end{tabular}

Data are presented as number of patients (\%) or mean [standard deviation] depending on the type of variable, whether qualitative or continuous, respectively. $(*)$ The $p$-value corresponds to the contrast of differences in proportions for qualitative variables and the non-parametric test of the Mann-Whitney U. $\left({ }^{* *}\right) \mathrm{CHA}_{2} \mathrm{DS}_{2-}$ VASC score only in patients with atrial fibrillation

${ }^{a} C C P$ complex chronic patient, ${ }^{b} / C H$ intracerebral haemorrhage, ${ }^{c} V K A$ vitamin $\mathrm{K}$ antagonists, ${ }^{\mathrm{d}} N O A C$ new oral anticoagulant, ${ }^{e} N S A I D$ non-steroidal anti-inflammatory drug, ${ }^{\text {f } S S R I ~ s e l e c t i v e ~ s e r o t o n i n ~ r e u p t a k e ~ i n h i b i t o r s, ~}{ }^{9} P P I$ Proton pump inhibitor 
Table $3 \mathrm{ICH}{ }^{\mathrm{a}}$ incidence by age groups in $\mathrm{CCP}^{\mathrm{b}}$ population

\begin{tabular}{lllllll}
\hline $\begin{array}{l}\text { Age } \\
\text { (years) }\end{array}$ & General Population* & CCP number & $\begin{array}{l}\text { HAS-BLED score } \\
\text { average }\end{array}$ & $\begin{array}{l}\text { CCP with HAS-BLED } \\
\text { score } \geq \mathbf{3}\end{array}$ & $\begin{array}{l}\text { ICH } \\
\text { episodes }\end{array}$ & $\begin{array}{l}\text { ICH Incidence } \\
\mathbf{1 0 , 0 0 0} \text { person-years }\end{array}$ \\
\hline $0-14$ & 24,099 & 3 & $0.7[0.6]$ & 1 & 0 & - \\
$15-44$ & 60,289 & 33 & $0.9[0.6]$ & $1(03.0)$ & 0 & - \\
$45-64$ & 50,259 & 182 & $1.9[1.1]$ & $49(26.9)$ & 5 & $1[0-2]$ \\
$65-74$ & 19,104 & 317 & $2.8[1.4]$ & $250(78.9)$ & 9 & $87[40-166]$ \\
$75-84$ & 13,231 & 903 & $3.3[1.2]$ & $792(87.7)$ & 38 & $116[82-159]$ \\
$\geq 85$ & 7839 & 2156 & $3.4[1.0]$ & $1797(83.3)$ & 123 & $166[138-198]$ \\
All & 174,821 & 3594 & $3.4[1.1]$ & $2890(80.4)$ & 161 & $151[127-174]$ \\
\hline
\end{tabular}

Data are presented as number of patients (\%), mean [standard deviation] or value [95\% confidence interval], depending on the type of variable, whether qualitative or continuous, respectively. $\left(^{*}\right)$ General population in the area of study, Terres de l'Ebre, Catalonia, Spain [see Additional file 2]

${ }^{\mathrm{a}} / \mathrm{CH}$ intracerebral haemorrhage, ${ }^{\mathrm{b}} \mathrm{CCP}$ complex chronic patient

$0.024-0.048]$ and a ROC curve with low accuracy [0.567; 95\% CI 0.526-0.608]. A HAS-BLED score $\leq 2$ showed the best Youden index (94.4).

\section{Discussion}

The results of the present study indicate a higher incidence of $\mathrm{ICH}$ in an emerging and vulnerable population subgroup, such as CCPs, than in both general and elderly populations. Data on time trends for $\mathrm{ICH}$ in the general population indicate no significant changes in the incidence of ICH over the last two decades $[6,15]$, but the incidence density of ICH was 5to-60-fold higher than that observed in the general population, both within the study area and worldwide (Table 6) [6, 16-24]. Comparisons between studies are difficult due to several interacting and overlapping emerging risk factors and aetiologies, new imaging techniques, demographic changes, comorbidities and associated treatments, different target populations, and the lack of a standardized methodology for data recording and exploitation, which makes it impossible to make adjustments to the incidences for different series of patients. Progressive demographic ageing and the inherent characteristics of CCPs could explain these results in $\mathrm{ICH}$ incidence [25]. Nevertheless, in the near future, the $\mathrm{ICH}$ incidence might be influenced by increases in the percentage of prescriptions of new anticoagulants (NOACs) and improvements in the cardiovascular risk approach.

Little information about sex-related differences in $\mathrm{ICH}$ is currently available, but it appears that the incidence of ICH could be influenced by interactions between sex and other factors. The present study showed some sexrelated clinical differences in a large database of $\mathrm{ICH}$ patients and thus adds accurate data to a topic for which limited information is available in the current literature, such as a higher prevalence of antiplatelet drug therapy among men. However, unlike the results obtained by other researchers, no significant differences in the incidence of $\mathrm{ICH}$ were found after sex stratification [26].
These data contrast with the results from a systematic review of 17 epidemiological studies, which reported a higher overall incidence of ICH in men [27]. Most likely, the presence of sex differences in risk factors encourages us to think about different approaches and the need for specific methods to assess the risk for ICH in CCPs.

Among the multiple ICH risk factors $[5,28]$, those eligible for intervention stand out: HAS-BLED score $\geq 3$, hypercholesterolemia and cardiovascular disease independently increased the risk of $\mathrm{ICH}$, whereas the use of statins and the diagnosis of heart failure were identified as protective factors. These results reflect an insufficient control of modifiable risk factors. Regarding the relationship between hypercholesterolemia, statin use and $\mathrm{ICH}$ risk, the available evidence indicates contradictory results in both primary and secondary prevention [29, 30]. Heart failure has been identified as a comorbidity but not a protective factor [31]. There is no clear interpretation of the risk of $\mathrm{ICH}$ in the context of heart failure or of the role of low blood pressure as a preventive factor for $\mathrm{ICH}$ because the data describing the optimal BP goals in patients with $\mathrm{HF}$ are limited and contradictory $[32,33]$. However, the risk of $\mathrm{ICH}$ could be related to the concurrence of atrial fibrillation and a greater or lesser indication of antiplatelet and anticoagulant therapy. Neither HT nor antiplatelet therapy were recognized $\mathrm{ICH}$ risk factors $[34,35]$ that appeared explicitly in our model. Nevertheless, these are included in the HASBLED score, among other common bleeding risk factors. However, neither the degree of control nor the severity or duration of other cardiovascular risk factors was investigated, nor the cardiovascular risk was not measured quantitatively.

The HAS-BLED score is a useful tool for close periodic monitoring and for checking avoidable risk factors [36]. Despite its low estimated discriminative power, a HAS-BLED score $\geq 3$ showed high sensitivity and a negative predictive value for the risk of $\mathrm{ICH}$. This result is of special interest from a clinical point of view because it introduces the concept of "unnecessarily premature and 
Table 4 Incidence Rate Ratio for $\mathrm{ICH}^{\mathrm{a}}$ risk factors in the $\mathrm{CCP}^{\mathrm{b}}$ population

\begin{tabular}{|c|c|c|}
\hline Age & $\begin{array}{l}\text { Incidence } \\
10,000 \text { person-years }\end{array}$ & $\begin{array}{l}\text { Incidence Rate Ratic } \\
\text { (exposed vs unexpo }\end{array}$ \\
\hline$\geq 80$ years & $101(85-120)$ & $1.5(0.9-2.2)$ \\
\hline$<80$ years & $69(46-100)$ & \\
\hline \multicolumn{3}{|c|}{ Cardiovascular risk factors } \\
\hline \multicolumn{3}{|c|}{ Arterial hypertension } \\
\hline Yes & $99(83-117)$ & $1.6(1.1-2.5)$ \\
\hline No & $61(40-89)$ & \\
\hline \multicolumn{3}{|l|}{ Diabetes } \\
\hline Yes & $384(292-497)$ & $0.7(0.6-1.1)$ \\
\hline No & $99(81-120)$ & \\
\hline \multicolumn{3}{|c|}{ Hypercholesterolemia } \\
\hline Yes & $104(83-128)$ & $1.4(0.9-1.8)$ \\
\hline No & $77(60-97)$ & \\
\hline \multicolumn{3}{|c|}{ Comorbidities } \\
\hline \multicolumn{3}{|c|}{ Cardiovascular disease $^{*}$} \\
\hline Yes & $112(86-145)$ & $1.4(1.0-1.9)$ \\
\hline No & $80(65-97)$ & \\
\hline \multicolumn{3}{|c|}{ Ischaemic cardiopathy } \\
\hline Yes & $98(67-138)$ & $1.2(0.8-1.8)$ \\
\hline No & $86(72-103)$ & \\
\hline \multicolumn{3}{|c|}{ Peripheral arterial disease } \\
\hline Yes & $111(65-178)$ & $1.3(0.7-2.1)$ \\
\hline No & $88(74-103)$ & \\
\hline \multicolumn{3}{|c|}{ Ischaemic stroke } \\
\hline Yes & $116(67-189)$ & $1.3(0.8-2.2)$ \\
\hline No & $88(74-103)$ & \\
\hline \multicolumn{3}{|c|}{ Heart Failure } \\
\hline Yes & $72(50-100)$ & $0.7(0.5-1.1)$ \\
\hline No & $96(80-114)$ & \\
\hline \multicolumn{3}{|c|}{ Falls (background) } \\
\hline Yes & $83(51-126)$ & $0.9(0.6-1.4)$ \\
\hline No & $91(76-107)$ & \\
\hline \multicolumn{3}{|c|}{ HAS-BLED score } \\
\hline$\geq 3$ & $104(88-122)$ & $3.3(1.8-6.1)$ \\
\hline$<3$ & $31(16-56)$ & \\
\hline \multicolumn{3}{|l|}{ Medication } \\
\hline \multicolumn{3}{|l|}{ NOAC } \\
\hline Yes & $57(12-165)$ & $0.4(0.1-1.4)$ \\
\hline No & $130(110-151)$ & \\
\hline \multicolumn{3}{|l|}{$V K A^{d}$} \\
\hline Yes & $103(77-134)$ & $1.2(0.9-1.7)$ \\
\hline No & $84(69-102)$ & \\
\hline \multicolumn{3}{|c|}{ Antiplatelet drugs } \\
\hline Yes & 107 (88-130) & $1.5(1.1-2.1)$ \\
\hline
\end{tabular}


Table 4 Incidence Rate Ratio for $\mathrm{ICH}^{\mathrm{a}}$ risk factors in the $\mathrm{CCP}{ }^{\mathrm{b}}$ population (Continued)

\begin{tabular}{clc}
\hline Age & $\begin{array}{l}\text { Incidence } \\
\mathbf{1 0 , 0 0 0} \text { person-years }\end{array}$ & $\begin{array}{l}\text { Incidence Rate Ratio } \\
\text { (exposed vs unexposed) }\end{array}$ \\
\hline No & $69(53-90)$ & $0.9(0.6-1.2)$ \\
Statins & & \\
Yes & $85(68-105)$ & \\
No & $96(75-120)$ & \\
\hline
\end{tabular}

Data are presented as value (95\% confidence interval). ( $\left.{ }^{*}\right)$ Cardiovascular disease includes ischemic cardiopathy and/or peripheral arterial disease and/or ischemic stroke and/or transient ischemic accident

${ }^{\mathrm{a}} \mathrm{ICH}$ intracerebral haemorrhage, ${ }^{\mathrm{b}} \mathrm{CCP}$ complex chronic patient, ${ }^{\mathrm{c}} \mathrm{NOAC}$ direct oral anticoagulant, ${ }^{\mathrm{d}}$ VKA vitamin $\mathrm{K}$ antagonists

avoidable mortality" for an episode of $\mathrm{ICH}$ as an indicator of the healthcare that these patients receive $[18,37]$. Further research related to the sensitivity and specificity of the HAS-BLED score for the identification of ICH risk in CCPs should be performed to detect the best cut-off point for not only detection but also strategy planning. Using this approach, different HAS-BLED scores could lead to various preventive measures, which could range from optimizing HT control to deprescription of NSAI Ds and antiplatelet drugs, particularly in the primary prevention of cardiovascular disease. A similar approach has been used regarding the prescription of statins to patients with a prior ICH episode [38]. Currently, there is an extensive trend towards optimization of the drug regimen of elderly patients, although a systematic and evidence-based approach has not yet been developed [39].

In this context, it is interesting to note that in the present study, $86.7 \%$ of patients with ICH and a HASBLED score $\geq 3$ were hypertensive, and $93.3 \%$ had an active prescription of NSAIDs and/or antiplatelet drugs. The use of NSAIDs [40] and antiplatelet therapy with respect to the risk of $\mathrm{ICH}$ has been recognized, and

Table $\mathbf{5}$ Independent $\mathrm{ICH}^{\mathrm{a}}$ risk factors for the entire $\mathrm{CCP}$ population and by sex

\begin{tabular}{llll}
\hline & Total & Women & Men \\
\hline HAS-BLED score $\geq 3$ & $3.5(1.9-6.7)$ & $4.2(1.7-10.7)$ & $2.9(1.2-7.1)$ \\
Hypercholesterolemia & $1.6(1.1-2.4)$ & $2.1(1.2-3.5)$ & $1.2(0.7-2.1)$ \\
Cardiovascular disease $^{*}$ & $1.5(1.1-2.1)$ & $1.1(0.6-1.7)$ & $2.2(1.3-3.6)$ \\
Statins & $0.6(0.4-0.9)$ & $0.6(0.4-1.0)$ & $0.6(0.3-1.1)$ \\
Heart failure & $0.6(0.4-0.9)$ & $0.7(0.4-1.1)$ & $0.5(0.3-1.0)$ \\
NOAC $^{d}$ & $0.5(0.1-1.6)$ & $0.2(0.0-1.6)$ & $0.9(0.2-3.9)$ \\
VKA $^{c}$ & $1.2(0.9-1.7)$ & $1.6(1.0-2.6)$ & $0.9(0.5-1.6)$ \\
Falls (background) & $0.9(0.5-1.4)$ & $0.9(0.5-1.5)$ & $0.7(0.3-1.9)$ \\
Age $\geq 80$ years & $1.3(0.9-2.1)$ & $2.3(1.2-4.6)$ & $0.9(0.6-1.6)$ \\
Diabetes & $0.7(0.5-1.0)$ & $0.6(0.4-1.0)$ & $0.9(0.5-1.5)$ \\
\hline
\end{tabular}

Data are presented as odds ratio (95\% confidence interval)

$(*)$ Cardiovascular disease includes ischemic cardiopathy and/or peripheral arterial disease and/or ischemic stroke and/or transient ischemic accident) ${ }^{a} / C H$ intracerebral haemorrhage, ${ }^{b} C C P$ complex chronic patient, ${ }^{C} V K A$ vitamin $\mathrm{K}$ antagonists, ${ }^{\mathrm{d}}$ NOAC direct oral anticoagulant evidence suggests that this effect might not be dosedependent [41]. These drugs interact by impairing thromboxane-dependent platelet aggregation and can thus prolong the bleeding time [42]. Moreover, $53.4 \%$ of the CCP population had an active antiplatelet prescription, although only $29.2 \%$ of the patients had suffered ischaemic cardiopathy and $7.7 \%$ suffered an ischaemic stroke and/or transient ischaemic accident. The antiplatelet drugs are probably prescribed not only for secondary prevention but also for primary prevention. The benefits of antiplatelet therapy for the secondary prevention of cardiovascular disease clearly outweigh the risks of bleeding, and low-dose aspirin is consistently recommended in this setting. However, no clear consensus exists regarding whether, and if so for whom, antiplatelet therapy is appropriate for the primary prevention of cardiovascular disease, which has led to different recommendations in the organizational guidelines [43, 44]. The lack of evidence regarding the effects of these recommendations is even greater in the older population. The ACC/AHA Guidelines do not recommend aspirin as a primary prevention strategy for adults older than 70 years of age because it results in a significantly higher risk of major haemorrhage and does not result in a significantly lower risk of cardiovascular disease than placebo $[45,46]$. Bleeding complications are an inherent risk in anticoagulant and thrombolytic treatments, and the benefits and risks are strongly correlated [44]. This balance leads to complex decisions, particularly in a population such as CCPs, which is defined by its complexity. Having a tool for identifying those patients with a higher risk of ICH would help improve this decision process, among others. The fact that antiplatelet drugs but not anticoagulant drugs were associated with a high risk of $\mathrm{ICH}$ could be due to the use of the latter in a smaller group of cases ( $29.2 \%$ vs $53.4 \%)$, which leads to a more difficult detection of significant differences. It is likely that the cardiovascular profile risk of those patients with prescriptions of these drugs is different, as suggested by the data in the comparative tables.

The control of comorbidities, such as cardiovascular disease, hypercholesterolemia and HT, should also be prioritized in the follow-up of CCPs. However, it should 
Table 6 Comparative ICH annual incidence per 10,000 person/years

\begin{tabular}{|c|c|c|c|}
\hline Author (year) & Studied population & $\begin{array}{l}\mathrm{ICH}^{\mathrm{a}} \text { incidence } \\
10,000 \text { person-years }\end{array}$ & \\
\hline \multirow[t]{3}{*}{ Current study (2020) } & $C C P^{b}$ population & 150.6 & {$[127.3-174.7]$} \\
\hline & $<80$ years & 111.6 & {$[111.5-111.6]$} \\
\hline & $\geq 80$ years & 162.4 & {$[162.4-162.5]$} \\
\hline González (2016) [18] & $>18$ years & 2.3 & {$[2.1-2.7]$} \\
\hline Carlsson (2016) [19] & $\geq 75$ years & 24.2 & {$[19.5-28.9]$} \\
\hline Jolink (2015) [20] & $75-94$ years & 17.6 & {$[11.0-28.0]$} \\
\hline \multirow[t]{3}{*}{ Krishnamurthi (2014) [21] } & All ages & & \\
\hline & -High-income countries & 4.8 & {$[4.5-5.2]$} \\
\hline & -Low-income countries & 8.1 & [7.3-9.3] \\
\hline Stein (2012) [22] & $\geq 80$ years & 12.5 & {$[11.0-14.04]$} \\
\hline Van Asch (2010) [6] & $>45$ years & 2.4 & {$[1.9-3.1]$} \\
\hline \multirow[t]{3}{*}{ Lovelock (2007) [23] } & $\geq 75$ years & & \\
\hline & OCSPC & 15.5 & {$[9.6-21.3]$} \\
\hline & OXVASC $^{d}$ & 14.4 & {$[9.5-19.2]$} \\
\hline \multirow[t]{4}{*}{ Sudlow (1997) [24] } & $45-84$ years & & \\
\hline & Total & $3.0-7.9$ & {$[2.1-11.4]$} \\
\hline & $\mathrm{PICH}^{\mathrm{e}}$ & $2.6-6.0$ & \\
\hline & $\mathrm{SAH}^{f}$ & $0.4-1.9$ & \\
\hline
\end{tabular}

Data are presented as value [95\% confidence interval]

${ }^{a} / C H$ intracerebral haemorrhage, ${ }^{b} C C P$ complex chronic patient, ${ }^{c}$ OCPS Oxford Community Stroke Project, ${ }^{d}$ OXVASC Oxford Vascular Study, ${ }^{\text {e } P I C H ~ P r i m a r y ~}$ intracerebral haemorrhage, ${ }^{\text {f }} \mathrm{SAH}$ Subarachnoid haemorrhage

be considered that some inherent characteristics of these patients, such as institutionalization, cognitive impairment, or polypharmacy, might eventually be barriers to achieving optimal control [14].

Although patients with cardiovascular disease are expected to obtain HAS-BLED scores $\geq 3$, the coexistence of different factors, such as advanced age, multimorbidity and polypharmacy, together with a higher incidence of ICH in CCPs would justify the individual, systematic and regular use of risk assessment tools for the detection of high-risk cases, although these might come with a high rate of false positives. Unfortunately, empirical evidence in this field is limited despite the clinical relevance of ICH and its associated adverse outcomes. This study adds to the available knowledge in an area of work that is considered very challenging due to the greater and new needs of CCPs and therefore offers an opportunity to explore clinical risk assessment modalities and prevention policies to attempt to reduce the prevalence and severity of diseases, in accordance to the suggested key points of the latest report from the European Stroke Organization, the Stroke Alliance for Europe and the World Health Organization $[8,47,48]$.

Because ICH is a heterogeneous disease, this study has some limitations, such as those related to the possibility of underregistration. The information source did not allow differentiation of the type of
$\mathrm{ICH}$, its aetiology, or its severity. Hypertensive vasculopathy is the most common cause of spontaneous $\mathrm{ICH}$, and the main factor in preventing recurrence is blood pressure control [49]. Regardless of these facts, a more accurate classification of stroke into a pathogenic subtype evades the best clinical skills when the main goal is its prevention. For this reason, ICH subtype was not considered a useful variable in the risk assessment, although a better understanding of the underlying causes of the different subtypes is needed. The lack of comparative data in relation to some factors associated with the incidence of $\mathrm{ICH}$, particularly those related to antiplatelet drugs and their combination with NOACs and/or other treatments should be considered. Furthermore, our results are based on a CCP population and might not be applicable to other populations. More studies are needed to evaluate the impact on the detection of those high-risk cases when adjusted by morbidity groups [50]. Finally, the usefulness and cost-effectiveness of a risk scale in daily clinical practice related to the incidence of $\mathrm{ICH}$ and its consequences should be evaluated [8].

\section{Conclusions}

- The incidence of intracerebral haemorrhage in a complex chronic patient population was $151 / 10,000 /$ 
year (95\% CI: 127-174), which is 5-to-60-fold higher than the incidence reported for the general population.

- In the population of complex chronic patients, the main risk factors associated with intracerebral haemorrhage were HAS-BLED score $\geq 3$ and history of hypercholesterolemia and cardiovascular disease.

- The systematic evaluation of bleeding risk based on the HAS-BLED score or similar scores in complex chronic patients could be useful for the identification of individuals with a high risk of intracerebral haemorrhage, i.e., those who can benefit the most from optimizing the control of modifiable factors.

\section{Supplementary Information}

The online version contains supplementary material available at https://doi. org/10.1186/s12877-021-02004-4.

\section{Additional file 1.}

Additional file 2 .

\section{Abbreviations}

BP: Blood pressure; CCP: Complex chronic patient; Cl: Confidence interval; eSAP: Electronic clinical records in primary care; CMBD: Minimum basic data set, Catalan acronym for Conjunt Mínim Bàsic de Dades; HT: Arterial hypertension; HF: Heart failure; ICD-10: International Classification of Diseases; ICH: Intracerebral haemorrhage; INR: International normalized ratio; IRR: Incidence rate ratio; MACA: Advanced Chronic Care Model, Catalan acronym for Model d'Atenció a la Cronicitat Avanzada; NOACs: New oral anticoagulants; NSAID: Nonsteroidal anti-inflammatory drugs; OR: Odds ratio; PIIC: Shared Individualized Intervention Plan, Catalan acronym for Pla d'Intervenció Individualitzat Compartit; SIRE: Integrated Electronic Prescription System, Catalan acronym for Sistema Integrat de Recepta Electrònica

\section{Acknowledgements}

\section{Not applicable.}

Ebrictus ${ }^{8}$ Group Research Group.

Ma Lluïsa Queralt-Tomas ${ }^{9}$, Anna Panisello-Tafalla ${ }^{10}$, Jorgina Lucas-Noll ${ }^{11}$

${ }^{8}$ Ebrictus Reserach Group. Fundació Institut Universitari per a la recerca a

I'Atenció Primària de Salut Jordi Gol i Gurina (IDIAPJGol). Barcelona, Spain.

${ }^{9}$ Primary care EAP Tortosa-Oest. Institut Català de la Salut. Catalonia, Spain.

${ }^{10}$ Primary care EAP Tortosa-Est. Institut Català de la Salut. Catalonia, Spain.

${ }^{11}$ Primary care SAP Terres de I'Ebre. Institut Català de la Salut. Catalonia, Spain.

\section{Authors' contributions}

Conceptualization, B.L-C., JL.C-E., A.G-H., J.B-O., FM.M-L.; Data curation, B.L-C., E.M-S., J.B-O., J.F-S; Formal analysis, B.L-C., JL.C-E., FM.ML; J.F-S; Funding acquisition, B.L-C., JL.C-E and Group Research EBRICTUS; Investigation, B.L-C., JL.C-E., FM.M-L J.B-O., and Group Research EBRICTUS; Methodology, B.L-C., JL.C-E., FM.M-L.; J.F-S; Project administration, B.L-C.,. J.-L.C.-E., FM.M-L; Resources, B.L-C., and Group Research EBRICTUS; Supervision, JL.C-E., FM.M-L; Validation, B.L-C., JL.C-E., J.F-S., FM.M-L; Visualization, B.L-C., JL.C-E., FM.M-L.; J.F.-S.; Writing-original draft, B.L-C., JL.C-E., A.G-H., FM.M-L.; Writing-review and editing, B.L-C., JL.C-E., FM.M-L and Group Research EBRICTUS. All authors have read and agreed to the published version of the manuscript.

\section{Funding}

The present study was funded by a scholarship obtained through the specific collaboration agreement between the Catalan Health Institute (Terres de l'Ebre Territorial Management) and the Rovira i Virgili University for the preparation of a doctoral dissertation, in accordance to Resolution EMC/581/ 2019 of 28th February 2019 and published in the DOGC (Official Journal of the Generalitat de Catalonia) No. 7829 on 13th March 2019 (Dl-2019). This research received no specific grant from funding agencies in the commercial or for-profit sectors.

\section{Availability of data and materials}

Currently, the datasets used and/or analysed during the current study are available from the corresponding author upon reasonable request. All data generated or analysed during this study have been deposited in the public repository: doi:https://doi.org/10.5061/dryad.0hr311d.

\section{Ethics approval and consent to participate}

The protocol was approved by the Research Ethics Committee of the Jordi Gol University Institute for Research in Primary Care (IDIAP Jordi Gol) (Code P16/087), was retrospectively registered in ClinicalTrials.gov (NCT03247049) at August 11/2017, and complies with the Helsinki Declaration and the local ethics committee requirements for clinical research. To gather data from the study, registry information was collected from the government-run healthcare provider responsible for all inpatient care in the county without any contact with the participants. For this type of study, formal consent is not required, and the requirement for informed patient consent was waived prior to the inclusion of their medical data in this study.

\section{Consent for publication}

Not Applicable.

\section{Competing interests}

Not applicable.

\section{Author details}

${ }^{1}$ Department of Primary Care, Catalonian Health Institute, EAP Tortosa-est, UUDD Terres de I'Ebre; University Rovira Virgili, Tortosa, Spain. Department of Primary Care, Catalonian Health Institute, University Rovira i Virgili, CAP EI Temple, Plaça Carrilet s/n. 43500, Tortosa, Catalunya, Spain. ${ }^{3}$ Department of Primary Care, Catalonian Health Institute, EAP Amposta, Amposta, Spain. ${ }^{4}$ Department of Primary Care, Catalonian Health Institute, EAP Tortosa-est, UUDD Terres de I'Ebre, Tortosa, Spain. ${ }^{5}$ Department of Primary Care, Catalonian Health Institute, Fundació Institut Universitari per a la recerca a I'Atenció Primària de Salut Jordi Gol i Gurina (IDIAPJGol), EAP Alcanar-Sant Carles de la Ràpita, Spain. 'Unitat de Suport a la Recerca Terres de l'Ebre, Fundació Institut Universitari per a la recerca a l'Atenció Primària de Salut Jordi Gol i Gurina (IDIAPJGol), Tortosa, Spain. ${ }^{7}$ Department of Primary Care, Catalonian Health Institute; Fundació Institut Universitari per a la recerca a I'Atenció Primària de Salut Jordi Gol i Gurina (IDIAPJGol); University Rovira i Virgili, Reus, Spain.

Received: 18 June 2020 Accepted: 1 January 2021

Published online: 05 February 2021

\section{References}

1. Beard JR, Officer A, de Carvalho IA, Sadana R, Pot AM, Michel JP, et al. The world report on ageing and health: a policy framework for healthy ageing Lancet. 2016;387(10033):2145-54. https://doi.org/10.1016/S01406736(15)00516-4.

2. Iglesias FH, Celada CA, Navarro CB, Morales LP, Visus NA, Valverde CC, et al for SABCOMP group. Complex Care Needs in Multiple Chronic Conditions: Population Prevalence and Characterization in Primary Care. A Study Protocol. Int J Integr Care. 2018;18(2):16. doi: https://doi.org/10.5334/ijic. 3292.

3. Blay C, Limón E. (Coord.) Bases para un modelo catalán de atención a las personas con necesidades complejas: conceptualización e introducción a los elementos operativos. [Internet]. Barcelona: Departament de Salut; 2020. Available from: http://salutweb.gencat.cat/web/.content/_ambits-actuacio/ Linies-dactuacio/Estrategies-de-salut/enapisc/enapisc-cronicitat-complexa. pdf (Accessed 26/June/2020)

4. Beard JR, Officer A, Cassels A. World report on ageing and health. Geneva: World Health Organization; 2015. [Internet] Available from: http://www.who. int/ageing/publications/world-report-2015/en/ (Accessed 26/June/2020).

5. An SJ, Kim TJ, Yoon BW. Epidemiology, risk factors, and clinical features of Intracerebral hemorrhage: An update. J Stroke. 2017;19(1):3-10. https://doi. org/10.5853/jos.2016.00864.

6. van Asch CJ, Luitse MJ, Rinkel GJ, van der Tweel I, Algra A, Klijn CJ. Incidence, case fatality, and functional outcome of intracerebral haemorrhage over time, according to age, sex, and ethnic origin: a systematic review and meta-analysis. Lancet Neurol. 2010;9(2):167-76. https://doi.org/10.1016/\$1474-4422(09)70340-0. 
7. Poon MT, Bell SM, Al-Shahi SR. Epidemiology of Intracerebral Haemorrhage. Front Neurol Neurosci. 2015;37:1-12. https://doi.org/10.1159/000437109.

8. Norrving B, Barrick J, Davalos A, Dichgans M, Cordonnier C, Guekht A, et al. Action plan for stroke in Europe 2018-2030. Eur Stroke J. 2018;3(4):309-36. https://doi.org/10.1177/2396987318808719.

9. Martínez de la Iglesia J, Dueñas Herrero R, Onís Vilches MC, Aguado Taberné C, Albert Colomer C, Luque Luque R. Adaptación y validación al castellano del cuestionario de Pfeiffer (SPMSQ) para detectar la existencia de deterioro cognitivo en personas mayores de 65 años. Med Clin (Barc). 2001;117(4): 129-34. https://doi.org/10.1016/s0025-7753(01)72040-4.

10. Sulter G, Steen C, De Keyser J. Use of the Barthel index and modified Rankin scale in acute stroke trials. Stroke. 1999;30(8):1538-41. https://doi.org/10. 1161/01.str.30.8.1538.

11. Bruno A, Shah N, Lin C, Close B, Hess DC, Davis K, et al. Improving modified Rankin scale assessment with a simplified questionnaire. Stroke. 2010;41(5): 1048-50. https://doi.org/10.1161/STROKEAHA.109.571562.

12. Pisters R, Lane DA, Nieuwlaat R, de Vos CB, Crijns HJ, Lip GY. A novel userfriendly score (HAS-BLED) to assess 1-year risk of major bleeding in patients with atrial fibrillation: the euro heart survey. Chest. 2010;138(5):1093-100. https://doi.org/10.1378/chest.10-0134.

13. Castini D, Persampieri S, Sabatelli L, Erba M, Ferrante G, Valli F, Centola M, Carugo S. Utility of the HAS-BLED score for risk stratification of patients with acute coronary syndrome. Heart Vessel. 2019 Oct;34(10):1621-30. https://doi. org/10.1007/s00380-019-01405-1.

14. ENAPISC. El procés asistencial d'atenció a la cronicitat i la complexitat a la xarxad'atenció primaria. Estratègia Nacional d'Atenció Primària i Salut Comunitària (ENAPISC). [Internet]. Barcelona: Departament de Salut, Generalitat de Catalunya; 2019. Available from: http://salutweb.gencat.cat/ web/.content/_ambits-actuacio/Linies-dactuacio/Estrategies-de-salut/ enapisc/enapisc-cronicitat-complexa.pdf (Accessed 20/August/2020).

15. Hesami O, Kasmaei HD, Matini F, Assarzadegan F, Mansouri B, Jabbehdari S. Relationship between intracerebral hemorrhage and diabetes mellitus: a case-control study. J Clin Diagn Res. 2015;9(4):OC08-10. https://doi.org/10. 7860/JCDR/2015/12226.3741

16. González-Henares MA, Clua-Espuny JL, Lorman-Carbo B, Fernández-Saez J, Queralt-Tomas L, Muria-Subirats E, et al. Risk of long-term mortality for complex chronic patients with Intracerebral hemorrhage: a populationbased e-cohort observational study. Adv Ther. 2020;37(2):833-46. https://doi. org/10.1007/s12325-019-01206-y.

17. González-Henares MA, Clua-Espuny JL, Queralt-Tomas MLL, Campo-Tamayo W, Muria-Subirats E, Panisello-Tafalla A, et al. Relationship between Hemorrhagic Stroke and Mortality in Chronic Complex Outpatients: Results from a Community Cohort of Patients. J Aging Sci. 2017;5(2):180. https://doi. org/10.14740/cr839.

18. Gonzalez-Henares A, Clua-Espuny JL, Gil-Guillen VF, Panisello-Tafalla A, Queralt-Tomas ML, Ripolles-Vicente R, et al. Incidencia y evitabilidad de los ictus hemorrágicos. Resultados del registro Ebrictus. Rev Neurol. 2016;62(9): 385-95. https://doi.org/10.33588/rn62092015470.

19. Carlsson $M$, Wilsgaard $T$, Johnsen $S H$, Vangen-Lønne $A$, Løchen $M,-L M$, Njølstad I, Mathiesen EB. Temporal trends in incidence and case fatality of Intracerebral hemorrhage: the Tromsø study 1995-2012. Cerebrovasc Dis Extra. 2016;6:40-9. https://doi.org/10.1159/000447719.

20. Jolink WM, Klijn CJ, Brouwers PJ, Kappelle LJ, Vaartjes I. Time trends in incidence, case fatality, and mortality of intracerebral hemorrhage. Neurology. 2015;85:1318-24. https://doi.org/10.1212/WNL. 0000000000002015 .

21. Krishnamurthi RV, Moran AE, Forouzanfar MH, Bennett DA, Mensah GA, Lawes $C M$, et al. The global burden of hemorrhagic stroke: a summary of findings from the GBD 2010 study. Glob Heart. 2014;9:101-6. https://doi.org/ 10.1016/j.gheart.2014.01.003.

22. Stein M, Misselwitz B, Hamann GF, Scharbrodt W, Schummer DI, Oertel MF. Intracerebral hemorrhage in the very old: future demographic trends of an aging population. Stroke. 2012;43(4):1126-8. https://doi.org/10.1161/ STROKEAHA.111.644716.

23. Lovelock CE, Molyneux AJ, Rothwell PM, Oxford Vascular Study. Change in incidence and aetiology of intracerebral haemorrhage in Oxfordshire, UK, between 1981 and 2006: a population-based study. Lancet Neurol. 2007;6: 487-93. https://doi.org/10.1016/S1474-4422(07)70107-2.

24. Sudlow CLM, Warlow CP. Comparable Studies of the Incidence of Stroke and its Pathological Types. Stroke. 1997;28(3):491-9. https://doi.org/10.1161/ 01.STR.28.3.491.
25. Camacho E, LoPresti MA, Bruce S, Lin D, Abraham M, Appelboom G, Taylor B, McDowell M, DuBois B, Sathe M, Sander CE. The role of age in intracerebral hemorrhages. J ClinNeurosci. 2015;22(12):1867-70. https://doi. org/10.1016/j.jocn.2015.04.020.

26. Roquer J, Rodríguez-Campello A, Jiménez-Conde J, Cuadrado-Godia E, Giralt-Steinhauer E, Vivanco Hidalgo RM, et al. Sex-related differences in primary intracerebral hemorrhage. Neurology. 2016;87(3):257-62. https://doi. org/10.1212/WNL.0000000000002792.

27. Appelros $P$, Stegmayr B, Terént A. Sex differences in stroke epidemiology: a systematic review. Stroke. 2009;40(4):1082-90. https://doi.org/10.1161/ STROKEAHA.108.540781.

28. O'Donnell MJ, Xavier D, Liu L, Zhang H, Chin SL, Rao-Melacini P, et al. For INTERSTROKE investigators. Risk factors for ischaemic and intracerebral haemorrhagic stroke in 22 countries (the INTERSTROKE study): a casecontrol study. Lancet. 2010;376(9735):112-23. https://doi.org/10.1016/S01406736(10)60834-3.

29. Wang X, Dong Y, Qi X, Huang C, Hou L. Cholesterol levels and risk of hemorrhagic stroke: a systematic review and meta-analysis. Stroke. 2013; 44(7):1833-9. https://doi.org/10.1161/STROKEAHA.113.001326.

30. Gonzalez-Castellon MA, Marshall RS. Statin use and brain hemorrhage: real risk or unfounded fear? JAMA Neurol. 2014;71(11):1353-4. https://doi.org/10. 1001/jamaneurol.2014.2463.

31. Meschia JF, Bushnell C, Boden-Albala B, Braun LT, Bravata DM, Chaturvedi S, et al. for American Heart Association Stroke Council; Council on Cardiovascular and Stroke Nursing; Council on Clinical Cardiology; Council on Functional Genomics and Translational Biology; Council on Hypertension. Guidelines for the primary prevention of stroke: a statement for healthcare professionals from the American Heart Association/American Stroke Association. Stroke. 2014;45(12):3754-832. https://doi.org/10.1161/ STR.00000000000000046.

32. Biffi A, Anderson CD, Battey TW, Ayres AM, Greenberg SM, Viswanathan A, et al. Association between blood pressure control and risk of recurrent intracerebral hemorrhage. JAMA. 2015;314(9):904-12. https://doi.org/10. 1001/jama.2015.10082.

33. Oh GC, Cho HJ. Blood pressure and heart failure. Clin Hypertens. 2020;26:1. https://doi.org/10.1186/s40885-019-0132.

34. Chiquete E, Ruiz-Sandoval MC, Alvarez-Palazuelos LE, Padilla-Martínez JJ, González-Cornejo S, Ruiz-Sandoval JL. Hypertensive intracerebral hemorrhage in the very elderly. Cerebrovasc Dis. 2007;24(2-3):196-201. https://doi.org/10.1159/000104477.

35. García-Rodríguez LA, Martín-Pérez M, Hennekens CH, Rothwell PM, Lanas A. Bleeding risk with long-term low-dose aspirin: a systematic review of observational studies. PLoSOne. 2016;11(8):e0160046. https://doi.org/10. 1371/journal.pone.0160046.

36. Lip GY, Lane DA. Bleeding risk assessment in atrial fibrillation: observations on the use and misuse of bleeding risk scores. J Thromb Haemost. 2016; 14(9):1711-4. https://doi.org/10.1111/jth.13386.

37. Melchor I, Nolasco A, García-Senchermes C, Pereyra-Zamora P, Pina JA, Moncho J, et al. Avoidable mortality. Changes in the new century? Gac Sanit. 2008;22(3):200-9. https://doi.org/10.1157/13123965.

38. Ribe $\mathrm{AR}$, Vestergaard $\mathrm{CH}$, Vestergaard $\mathrm{M}$, Pedersen $\mathrm{HS}$, Prior $\mathrm{A}$, Lietzen LW, Brynningsen PK, Fenger-Grøn M. Statins and risk of Intracerebral hemorrhage in individuals with a history of stroke. Stroke. 2020;51(4):11119. https://doi.org/10.1161/STROKEAHA.119.027301.

39. Edey R, Edwards N, Von Sychowski J, Bains A, Spence J, Martinusen D. Impact of deprescribing rounds on discharge prescriptions: an interventional trial. Int J Clin Pharm. 2019;41 (1):159-66. https://doi.org/10.1007/s1 1096-018-0753-2.

40. Islam MM, Poly TN, Walther BA, Yang HC, Lin MC, Li YC. Risk of hemorrhagic stroke in patients exposed to nonsteroidal anti-inflammatory drugs: a metaanalysis of observational studies. Neuroepidemiology. 2018;51(3-4):166-76. https://doi.org/10.1159/000490741.

41. Serebruany VL, Steinhubl SR, Berger PB. Analysis of risk of bleeding complications after different doses of aspirin in 192,036 patients enrolled in 31 randomized controlled trials. Am J Cardiol. 2005;95:1218-22. https://doi. org/10.1016/j.amjcard.2005.01.049.

42. Gurbel P, Tantry U, Weisman S. A narrative review of the cardiovascular risks associated with concomitant aspirin and NSAID use. J Thromb Thrombolysis. 2019;47(1):16-30. https://doi.org/10.1007/s11239-018-1764-5.

43. Godley RW, Hernandez-Vila E. Aspirin for Primary and Secondary Prevention of Cardiovascular Disease. Tex Heart Inst J. 2016;43(4):318-9. Published 2016 Aug 1. https://doi.org/10.14503/THIJ-16-5807. 
44. Patrono C, Baigent C. Role of aspirin in primary prevention of cardiovascular disease. Nat Rev Cardiol. 2019;16(11):675-86. https://doi.org/10.1038/s41569019-0225-y.

45. Arnett DK, Blumenthal RS, Albert MA, Buroker AB, Goldberger ZD, Hahn EJ, et al. 2019 ACC/AHA guideline on the primary prevention of cardiovascular disease: a report of the American College of Cardiology/American Heart Association task force on clinical practice guidelines. Circulation. 2019; 140(11):e596-646. https://doi.org/10.1161/CIR.0000000000000678 [erratum in: circulation. 2019;140(11): e649-e650. Erratum in: circulation. 2020;141(4): e60. Erratum in: circulation. 2020;141(16): e774].

46. McNeil JJ, Wolfe R, Woods RL, Tonkin AM, Donnan GA, Nelson MR, et al. Effect of aspirin on cardiovascular events and bleeding in the healthy elderly. N Engl J Med. 2018;379(16):1509-18. https://doi.org/10.1056/ NEJMoa1805819.

47. Stevens E, Emmett E, Wang Y, McKevitt C, Wolfe CDA. The Burden of Stroke in Europe. Report. King's College London for the Stroke Alliance for Europe (SAFE). 2018. [Internet] Available from: http://www.strokeeurope.eu/ downloads/TheBurdenOfStrokelnEuropeReport.pdf (Accessed 02/August/ 2020).

48. Cerezo Cerezo J, Arias LC. Population stratification: A fundamental instrument used for population health management in Spain: World Health Organization; 2018. [Internet] Available from: https://www.euro.who.int/ data/assets/pdf_file/0006/364191/gpb-population-stratification-spain. pdf?ua=1 (Accessed 02/August/2020).

49. Diener HC, Hankey GJ. Primary and secondary prevention of ischemic stroke and cerebral hemorrhage: JACC focus seminar. J Am Coll Cardiol. 2020; 75(15):1804-18. https://doi.org/10.1016/j.jacc.2019.12.072.

50. Nnoaham KE, Cann KF. Can cluster analyses of linked healthcare data identify unique population segments in a general practice-registered population? BMC Public Health. 2020;20(1):798. https://doi.org/10.1186/ s12889-020-08930-z.

\section{Publisher's Note}

Springer Nature remains neutral with regard to jurisdictional claims in published maps and institutional affiliations.

Ready to submit your research? Choose BMC and benefit from:

- fast, convenient online submission

- thorough peer review by experienced researchers in your field

- rapid publication on acceptance

- support for research data, including large and complex data types

- gold Open Access which fosters wider collaboration and increased citations

- maximum visibility for your research: over $100 \mathrm{M}$ website views per year

At $\mathrm{BMC}$, research is always in progress.

Learn more biomedcentral.com/submissions 